\title{
Laparoscopic Management of Perforated Peptic Ulcer: Simple Closure or Something More?
}

\section{Periklis Karydakis ${ }^{1,2}$, Dmitry Iu. Semenov ${ }^{3}$, Alexandros V. Kyriakidis ${ }^{1,2}$, Zeynur Kh. Osmanov ${ }^{3}$, Iraklis Perysinakis ${ }^{4}$, Elena Did-Zurabova ${ }^{3}$, Yuriy S. Chekmasov ${ }^{3}$, Lyssandros Karydakis ${ }^{1}$, Vladimiros Kyriakidis ${ }^{1}$}

${ }^{1}$ Department of Surgery, “Sotiria” Chest Diseases Hospital, Athens, Greece

${ }^{2}$ Department of Surgery, "Sismanogleio" General Hospital, Athens, Greece

${ }^{3}$ General Surgery Clinic, Sant Petersburg State Medical University "I.P.Pavlov", Sant Petersburg, Russia

${ }^{4}$ Third Surgical Department, "HYGEIA” Hospital, Athens, Greece

Email: iraklisper@gmail.com

How to cite this paper: Karydakis, P., Semenov, D.Iu., Kyriakidis, A.V., Osmanov, Z.Kh., Perysinakis, I., Did-Zurabova, E., Chekmasov, Y.S., Karydakis, L. and Kyriakidis, V. (2016) Laparoscopic Management of Perforated Peptic Ulcer: Simple Closure or Something More? Open Journal of Gastroenterology, 6, 311-318.

http://dx.doi.org/10.4236/ojgas.2016.611034

Received: October 8, 2016

Accepted: November 6, 2016

Published: November 9, 2016

Copyright $\odot 2016$ by authors and Scientific Research Publishing Inc. This work is licensed under the Creative Commons Attribution International License (CC BY 4.0).

http://creativecommons.org/licenses/by/4.0/

(c) (i) Open Access

\begin{abstract}
Purpose: During the last decade laparoscopic approach to perforated peptic ulcer has gained wide acceptance over the traditional open repair on the basis of being an equally efficient and less invasive technique. Methods: 198 patients with perforated duodenal or prepyloric ulcer that were surgically treated from 2003 to 2014 were included in this study. 140 were operated within $2-6$ hours from the onset of symptoms, 55 within 6 - 24 hours, and 3 patients after 24 hours. Results: Laparoscopic simple closure with Graham patch was performed in 179 patients. In 19 patients with known chronic ulcer resistant to pharmacologic therapy, who were operated within 6 hours from the onset of symptoms, laparoscopic Taylor procedure was undertaken. Conversion to open repair was necessitated in four patients. The operating time was 40 - $100 \mathrm{~min}$ for the Graham patch repair and 120 - $155 \mathrm{~min}$ for the Taylor procedure. During follow-up, $48 \%$ of patients from the "Graham patch" group and no one from the "definitive procedure" group had recurrent ulcer. Conclusions: Laparoscopic treatment of perforated peptic ulcer is technically feasible and safe when performed by experienced surgeons. In certain cases more definitive procedures may achieve better long-term results.
\end{abstract}

\section{Keywords}

Peptic Ulcer Perforation, Laparoscopy, Graham Patch, Taylor Procedure, Recurrence Rate 


\section{Introduction}

Peptic ulcer disease (PUD) used to be a major cause of mortality due to related complications. Standard treatment was surgery, which was also associated with significant morbidity and mortality as well as high recurrence rate. Since the advent of proton pump inhibitors (PPIs) and Helicobacter Pylori eradication treatment the role of surgery has been limited to complicated disease. Nevertheless the rate of peptic ulcer perforation has remained stable and continues to represent a major cause of mortality especially in elderly patients with PUD [1] [2]. Laparoscopic as compared to open repair of perforated peptic ulcer (PPU) has been associated with more favorable outcome in several trials [3] [4]. The aim of this study was to present our experience in laparoscopic treatment of PPU using either laparoscopic Graham patch or laparoscopic Taylor procedure (posterior vagotomy and anterior seromyotomy).

\section{Materials and Methods}

Permission for the study was obtained from the Institutional Review Boards of the two hospitals in which the study took place. Informed consent was obtained from all individual participants included in the study. The study was performed in accordance with the 1964 Helsinki declaration and its later amendments. 198 patients that were treated laparoscopically for PPU from 2003 to 2015 in two high volume centers comprised the study population. All patients were diagnosed with PPU based on the findings of computed tomography with Gastrografin ${ }^{\oplus}$ (Schering, Berlin, Germany). Risk stratification was undertaken using Boey score (Table 1) [5]. Exclusion criteria included known gastric cancer or positive intraoperative frozen section biopsy, gastric outlet obstruction, bleeding peptic ulcer as well as previous surgery in the upper abdomen.

One hundred and forty patients were operated within $2-6$ hours after the onset of symptoms, 55 within 6 - 24 hours, two patients 54 hours and one patient 72 hours after the onset of symptoms. All patients underwent nasogastric aspiration and received cefuroxime and omeprazole preoperatively. Data regarding clinical history, demographics, timing of surgery, type of procedure, operating time, perioperative complications, reason for conversion, analgesic requirements, timing of introduction and transition to oral feeding and duration of postoperative hospitalization was collected in a retrospective manner from patients' records. Follow-up protocol included telephone interviews

Table 1. Boey score and related outcomes. Risk factors are: Concomitant severe medical illness, Preoperative shock and Duration of perforation $>24$ hours. Score varies between 0 and 3 (each factor scores 1 point if positive).

\begin{tabular}{ccc}
\hline Risk score & Mortality $($ OR $)$ & Morbidity $(O R)$ \\
\hline 1 & $8 \%(2.4)$ & $47 \%(2.9)$ \\
2 & $33 \%(3.5)$ & $75 \%(4.3)$ \\
3 & $38 \%(7.7)$ & $77 \%(4.7)$ \\
\hline
\end{tabular}

OR: Odds ratio. 
and, in case of recurrent symptoms, an upper GI endoscopy. Follow-up period ranged from one to five years (mean 26, median 18).

\section{Results}

Clinical characteristics of the patient population are presented in Table 2. In 179 patients laparoscopic closure was performed with Graham patch, by applying two or three interrupted stitches (Vicryl ${ }^{\otimes} 2-0$ suture) across the perforation site. Nineteen patients with clinical signs of mild peritonitis and history of proven chronic PUD, resistant to antisecretory and H. pylori eradication treatment (at least twice unsuccessful courses), who arrived at the hospital within the first 6 hours after the onset of symptoms, were treated with laparoscopic Taylor procedure [6]. Operative details are also presented in Table 2. In the first 74 cases from the "Graham patch" group operating time was 60 100 minutes; gradually the operating time was reduced to 40 - 60 minutes in the last 105 cases. In four patients conversion to open surgery was necessitated due to severe inflammation of the surrounding tissues. In these four patients simple closure with Graham patch was performed.

Table 2. Clinical characteristics of the patient population and operative details.

\begin{tabular}{|c|c|}
\hline Characteristic & Value \\
\hline Total number of patients & 198 \\
\hline \multicolumn{2}{|l|}{ Sex } \\
\hline Male (\%) & $145(73.2 \%)$ \\
\hline Female (\%) & $53(26.8 \%)$ \\
\hline Age (years), range (mean) & $23-90(46)$ \\
\hline \multicolumn{2}{|l|}{ Boey score } \\
\hline 0 & 129 \\
\hline 1 & 52 \\
\hline 2 & 13 \\
\hline 3 & 4 \\
\hline \multicolumn{2}{|l|}{ Site of perforation } \\
\hline Prepyloric area & 71 \\
\hline Duodenal bulb & 127 \\
\hline \multicolumn{2}{|c|}{ Type of operation (number of patients) } \\
\hline Lap Graham patch & 179 \\
\hline Lap Taylor & 19 \\
\hline \multicolumn{2}{|l|}{ Operative time (min), range (mean) } \\
\hline Lap Graham patch & $40-100(65)$ \\
\hline Lap Taylor & $120-155(143)$ \\
\hline Conversion (number of patients) & 4 \\
\hline
\end{tabular}


All patients underwent nasogastric aspiration for 1 to 3 days (mean, 2 days). Patients resumed liquid diet in 2 - 4 days and solid diet in 3 - 5 days. Median postoperative parenteral analgesic requirements were 3 doses of pethidine $1 \mathrm{mg} / \mathrm{kg}$ intramuscularly (range 1 - 8 doses). Postoperative hospital stay was 3 - 6 days; patients returned to full activity within 15 - 25 days postoperatively. Fifteen patients developed early complications. Wound related complications occurred in 8 patients. Pulmonary atelectasis occurred in 7 patients. An 86-year-old male patient, who presented 72 hours after the onset of symptoms, and underwent laparoscopic simple closure of perforated duodenal ulcer, finally died of septic shock in the third postoperative day.

Ninety three out of 179 patients with simple suture and all 19 patients with laparoscopic Taylor procedure were successfully followed up, while the rest 86 patients from the simple suture group were lost to follow-up. Forty five patients with laparoscopic Graham patch had recurrent ulcer at gastroscopy during follow-up (48.4\%). On the contrary no patient from the definitive procedure group had recurrent ulcer at gastroscopy during follow-up.

\section{Discussion}

PUD is a very common condition with a worldwide incidence of $15 \%-25 \%$ [2]. Peptic ulcer may occur at any age although it is exceedingly rare in children and adolescents. Effective therapies are available nowadays which eliminate the need for elective surgery [7]. These include PPIs and Helicobacter Pylori eradication treatment [8]. Perforation of peptic ulcer is a serious complication that requires emergency attention and management. PPU is treated by closure of the site of perforation. The open repair via laparotomy used to be the standard of care for PPU until last decade. Nowadays laparoscopic approach constantly gains place in the field of PPU management. In 1990 Mouret et al first described laparoscopic sutureless fibrin glue omental patch for perforated duodenal ulcer [8]. In the same year laparoscopic suture repair of PPU was introduced by Nathanson et al. [9]. Since then laparoscopic approach of PPU has gained wide acceptance. Several methods of laparoscopic PPU repair have been described since 1990.

Walsh et al. proposed sealing the perforation with omentum and then performing peritoneal lavage and drainage. The falciform ligament may be used when the omentum is short [10]. Another method that nowadays gains place in the field of laparoscopic repair of PPU is the suture repair. Biopsy of a duodenal ulcer is not necessary, while gastric ulcers necessitate sampling for histological exclusion of cancer. Absorbable or non-absorbable 2/0 or 3/0 sutures are usually used. An omental (Graham) patch is implemented to seal the perforation or otherwise fibrin glue can be applied [11] [12]. Automatic stapling devices, gelatin sponge or fibrin glue are alternative options to deal with the perforation site. The combination of laparoscopy and endoscopy has been also described [13]. The Taylor procedure (anterior lesser curve seromyotomy and posterior truncalvagotomy) has been suggested as a viable solution for the treatment of chronic gastroduodenal ulcers resistant to PPIs and $H$. pylori eradication schemes. Anterior lesser curve seromyotomy and posterior truncalvagotomy was first described by Taylor 
in 1979 as an open procedure while Katkhouda and Mouiel were the first to describe in 1991 its laparoscopical modification [6] [13]. This procedure is based on the fact that the branches of the nerve of Latarjet are divided from the esophagogastric junction to the crow's foot along the lesser curvature of the stomach. The neuronal branches of the Latarjet nerve run through the serosa not penetrating the gastric mucosa until two centimeters away from the angular incision of the lesser curvature. Posterior truncalvagotomy with anterior seromyotomy (Taylor operation) preserves the anterior vagal trunk and its hepatic division. Anterior seromyotomy can be performed by creating a partial thickness incision along the lesser curvature of the stomach. The mucosa should be exposed but not entered. The area is closed with a continuous suture to prevent postoperative leak [14] [15] [16] [17]. Urbano et al. suggested that the treatment of choice for PPU is the conservative Taylor procedure and laparoscopic drainage of the abdominal cavity [17]. Petrakis et al. showed in their study that laparoscopic stapling modified Taylor procedure (Gomez-Ferrer method) allows a more rapid, technically easier and radical performance of the operation with excellent long term results [18] [19]. The most important part of the laparoscopic procedure for the repair of perforated ulcer is the peritoneal lavage and drainage which should be done very thoroughly. The use of about 6 to 10 liters of warm saline is usually recommended while several authors suggest using at least 30 liters. Then the peritoneal cavity is usually drained although some authors advocate against this [20] [21] [22] [23]. Antibiotic therapy is administered for approximately five days or as needed, depending on the patient's general condition, as well as antisecretory therapy with intravenous PPIs [18] [24].

The surgeon's experience in laparoscopic surgery is definitely one of the most important factors for success [15] [25] [26]. Conventional simple closure of PPU necessitates an upper abdominal incision to perform a relatively simple repair. Laparoscopy results in better cosmetic result avoiding the unsightly surgical scar and is associated with significantly less wound infections. Laparoscopy offers the surgeon the opportunity to explore the peritoneal cavity with a reduced risk for adhesions and postoperative hernias than an open repair. As far as operating time is concerned, trials have shown that the relative advantage of open repair is diminished when comparison is confined to experienced laparoscopic surgeons. A randomized study performed by Siu et al. revealed that the operating time for laparoscopic repair is significantly shorter or the same with that of the open repair. This is due to surgeon's experience and development of modern irrigation systems [27]. In this cohort the operative time for Taylor procedure was compatible with those reported in literature. Other studies have shown that the use of postoperative analgesics is decreased after laparoscopic repair [28]. According to Siu et al. pain was less intense on days 1 and 3 in the laparoscopic repair group [27]. On the contrary, Lan et al. reported same pain intensities in both groups, stating that pain is mainly due to peritonitis rather than the incision itself. Randomized prospective studies have shown that postoperative hospital stay was shorter after laparoscopic repair but there is significant heterogeneity between these studies. Katkhouda et al. suggested that patients undergoing laparoscopic repair with Taylor procedure re- 
sume normal diet earlier, while other studies failed to show significant differences [14]. Last but not least laparoscopic repair also seems advantageous over open repair in terms of faster recovery and earlier return to normal activity. A metaanalyses by Lau et al. in 2004 summarized the results of 13 trials that compared outcomes after open and laparoscopic repair and concluded that laparoscopic repair should be the procedure of choice for patients with no Boey risk factors [16] [28].

Some studies have suggested that laparoscopy is not safe in the presence of prolonged peritonitis, due to higher incidence of postoperative septic complications. These include: postoperative suture leak, pneumonia, intrabdominal abscess formation and external fistula [29]. In this study, we did not encounter major septic complications, with the exception of the aforementioned 86-year old patient who was surely not the most suitable candidate for laparoscopic approach; indeed the decision for a minimally invasive procedure was made upon the severity of the patient's general condition and the fact that the operating team was quite experienced in laparoscopic surgery. Consequently the results of the present study suggest that laparoscopic Taylor procedure is safe and reliable. Preoperative risk factors that should be taken into consideration, according to our experience, include: shock on admission, delayed presentation, severe underlying medical illness, age above 75 years and, of course, poor expertise in laparoscopic surgery.

\section{Conclusion}

In conclusion, it is the authors' opinion that laparoscopic treatment of PPU is technically feasible and safe when performed by a surgeon well experienced in laparoscopy. Although laparoscopic simple closure with Graham patch remains the operation of choice in the majority of cases, the experienced surgeon should not hesitate to perform a definitive procedure such as Taylor procedure if indicated. The importance of performing a definitive procedure is indicated by the excellent long-term results reported in this study.

\section{Conflict of Interest}

All authors declare that they have no conflict of interest and that they received no funding for this research.

\section{Ethical Approval}

The study protocol was approved by the local ethics committee of scientific research in both hospitals in which the study took place and all patients gave their consent prior to the study. The study was performed in accordance with the 1964 Helsinki declaration and its later amendments.

\section{References}

[1] Cao, F., Li, J., Li, A., Fang, Y., Wang, Y.J. and Li, F. (2014) Nonoperative Management for Perforated Peptic Ulcer: Who Can Benefit? Asian Journal of Surgery, 37, 148-153. 
http://dx.doi.org/10.1016/j.asjsur.2013.10.002

[2] Soreide, K., Thorsen, K., Harrison, E.M., Bingener, J., Moller, M.H., Ohene-Yeboah, M., et al. (2015) Perforated Peptic Ulcer. Lancet, 386, 1288-1298. http://dx.doi.org/10.1016/S0140-6736(15)00276-7

[3] Karydakis, P.K.A., Svoronos, G., et al. (2010) Laparoscopic Management of Perforated Peptic Ulcer with Single Suture or Single Suture and Modified Taylor Procedure. Hellenic Journal of Surgery, 82, 325-329. http://dx.doi.org/10.1007/s13126-010-0051-5

[4] Potashov, L.V., Semenov, D., Ushveridze, D.G., Osmanov, Z., Chekmasov Iu, S. and Panina, A.V. (2005) Long-Term Results of Closure of Perforated Pyloro-Duodenal Ulcers. Vestnik khirurgii imeni I. I. Grekova, 164, 40-42.

[5] Boey, J., Choi, S.K., Poon, A. and Alagaratnam, T.T. (1987) Risk Stratification in Perforated Duodenal Ulcers. A prospective Validation of Predictive Factors. Annals of Surgery, 205, 22-26. http://dx.doi.org/10.1097/00000658-198701000-00005

[6] Taylor, T.V., Lythgoe, J.P., McFarland, J.B., Gilmore, I.T., Thomas, P.E. and Ferguson, G.H. (1990) Anterior Lesser Curve Seromyotomy and Posterior Truncal Vagotomy versus Truncal Vagotomy and Pyloroplasty in the Treatment of Chronic Duodenal Ulcer. British Journal of Surgery, 77, 1007-1009. http://dx.doi.org/10.1002/bjs.1800770917

[7] Nirula, R. (2014) Gastroduodenal Perforation. Surgical Clinics of North America, 94, 31-34. http://dx.doi.org/10.1016/j.suc.2013.10.002

[8] Mouret, P., Francois, Y., Vignal, J., Barth, X. and Lombard-Platet, R. (1990) Laparoscopic Treatment of Perforated Peptic Ulcer. British Journal of Surgery, 77, 1006.

http://dx.doi.org/10.1002/bjs.1800770916

[9] Nathanson, L.K., Easter, D.W. and Cuschieri, A. (1990) Laparoscopic Repair/Peritoneal Toilet of Perforated Duodenal Ulcer. Surgical Endoscopy, 4, 232-233. http://dx.doi.org/10.1007/BF00316801

[10] Walsh, C.J., Khoo, D.E. and Motson, R.W. (1993) Laparoscopic Repair of Perforated Peptic Ulcer. British Journal of Surgery, 80, 127.

[11] Halkic, N., Pescatore, P. and Gillet, M. (1999) Laparoscopic-Endoscopic Management of Perforated Pyloroduodenal Ulcer. Endoscopy, 31, S64-865.

[12] Kum, C.K., Isaac, J.R., Tekant, Y., Ngoi, S.S. and Goh, P.M. (1993) Laparoscopic Repair of Perforated Peptic Ulcer. British Journal of Surgery, 80, 535. http://dx.doi.org/10.1002/bjs.1800800441

[13] Katkhouda, N. and Mouiel, J. (1991) A New Technique of Surgical Treatment of Chronic Duodenal Ulcer without Laparotomy by Videocoelioscopy. American Journal of Surgery, 161, 361-364. http://dx.doi.org/10.1016/0002-9610(91)90598-8

[14] Katkhouda, N., Mavor, E., Mason, R.J., Campos, G.M., Soroushyari, A. and Berne, T.V. (1999) Laparoscopic Repair of Perforated Duodenal Ulcers: Outcome and Efficacy in 30 Consecutive Patients. Archives of Surgery, 134, 845-848; Discussion 9-50. http://dx.doi.org/10.1001/archsurg.134.8.845

[15] Lau, H. (2004) Laparoscopic Repair of Perforated Peptic Ulcer: A Meta-Analysis. Surgical Endoscopy, 18, 1013-1021. http://dx.doi.org/10.1007/s00464-003-8266-y

[16] Chung, S.C. and Li, A.K. (1997) Helicobacter Pylori and Peptic Ulcer Surgery. British Journal of Surgery, 84, 1489-1490. http://dx.doi.org/10.1002/bjs.1800841102

[17] Urbano, D., Rossi, M., De Simone, P., Berloco, P., Alfani, D. and Cortesini, R. (1994) Alternative Laparoscopic Management of Perforated Peptic Ulcers. Surgical Endoscopy, 8, 1208-1211. http://dx.doi.org/10.1007/BF00591052 
[18] Petrakis, I., Vassilakis, S.J. and Chalkiadakis, G. (1999) Anterior Lesser Curve Seromyotomy Using a Stapling Device and Posterior Truncal Vagotomy for the Treatment of Chronic Duodenal Ulcer: Longterm Results. Journal of the American College of Surgeons, 188, 623628. http://dx.doi.org/10.1016/S1072-7515(99)00034-4

[19] Petrakis, I., Vassilakis, S.J., Vrachassotakis, N., Koutsoumpas, V. and Chalkiadakis, G. (1999) Laparoscopic Modified Taylor Procedure in the Treatment of Duodenal Ulcer: Technique and Outcome after 5-Year Follow-Up. European Surgical Research, 31, 471-479. http://dx.doi.org/10.1016/S1072-7515(99)00034-4

[20] Seelig, M.H., Seelig, S.K., Behr, C. and Schonleben, K. (2003) Comparison between Open and Laparoscopic Technique in the Management of Perforated Gastroduodenal Ulcers. Journal of Clinical Gastroenterology, 37, 226-229. http://dx.doi.org/10.1097/00004836-200309000-00007

[21] Lagoo, S., McMahon, R.L., Kakihara, M., Pappas, T.N. and Eubanks, S. (2002) The Sixth Decision Regarding Perforated Duodenal Ulcer. JSLS, 6, 359-368.

[22] Karydakis, P., Kyriakidis, A., Oikonomou, N., Argeitis, V., Fotopoulos, A., Karkaletsis, A., et al. (2000) Laparoscopic Management of Acute Abdomen. Surgical Endoscopy, 14, s14.

[23] Pai, D., Sharma, A., Kanungo, R., Jagdish, S. and Gupta, A. (1999) Role of Abdominal Drains in Perforated Duodenal Ulcer Patients: A Prospective Controlled Study. ANZ Journal of Surgery, 69, 210-213. http://dx.doi.org/10.1046/j.1440-1622.1999.01524.x

[24] Lunevicius, R. and Morkevicius, M. (2005) Systematic Review Comparing Laparoscopic and Open Repair for Perforated Peptic Ulcer. British Journal of Surgery, 92, 1195-1207.

http://dx.doi.org/10.1002/bjs.5155

[25] Lau, W.Y., Leung, K.L., Kwong, K.H., Davey, I.C., Robertson, C., Dawson, J.J., et al. (1996) A Randomized Study Comparing Laparoscopic versus Open Repair of Perforated Peptic Ulcer Using Suture or Sutureless Technique. Annals of Surgery, 224, 131-138. http://dx.doi.org/10.1097/00000658-199608000-00004

[26] Shelat, V.G., Ahmed, S., Chia, C.L. and Cheah, Y.L. (2015) Strict Selection Criteria during Surgical Training Ensures Good Outcomes in Laparoscopic Omental Patch Repair (LOPR) for Perforated Peptic Ulcer (PPU). International Surgery, 100, 370-375. http://dx.doi.org/10.9738/INTSURG-D-13-00241.1

[27] Siu, W.T., Chau, C.H., Law, B.K., Tang, C.N., Ha, P.Y. and Li, M.K. (2004) Routine Use of Laparoscopic Repair for Perforated Peptic Ulcer. British Journal of Surgery, 91, 481-484. http://dx.doi.org/10.1002/bjs.4452

[28] Zhou, C., Wang, W., Wang, J., Zhang, X., Zhang, Q., Li, B. and Xu, Z. (2015) An Updated Meta-Analysis of Laparoscopic Versus Open Repair for Perforated Peptic Ulcer. Scientific Reports, 5, Article No. 13976. http://dx.doi.org/10.1038/srep13976

[29] Muller, M.K., Wrann, S., Widmer, J., Klasen, J., Weber, M. and Hahnloser, D. (2016) Perforated Peptic Ulcer Repair: Factors Predicting Conversion in Laparoscopy and Postoperative Septic Complications. World Journal of Surgery, 40, 2186-2193.

http://dx.doi.org/10.1007/s00268-016-3516-Z 
Submit or recommend next manuscript to SCIRP and we will provide best service for you:

Accepting pre-submission inquiries through Email, Facebook, LinkedIn, Twitter, etc.

A wide selection of journals (inclusive of 9 subjects, more than 200 journals)

Providing 24-hour high-quality service

User-friendly online submission system

Fair and swift peer-review system

Efficient typesetting and proofreading procedure

Display of the result of downloads and visits, as well as the number of cited articles

Maximum dissemination of your research work

Submit your manuscript at: http://papersubmission.scirp.org/

Or contact ojgas@scirp.org 